\title{
Article \\ Hydrometallurgical Leaching of Copper Flash Furnace Electrostatic Precipitator Dust for the Separation of Copper from Bismuth and Arsenic
}

\author{
Michael Caplan ${ }^{1, *}$, Joseph Trouba ${ }^{1}$, Corby Anderson ${ }^{1}$ and Shijie Wang ${ }^{2}$ \\ 1 Kroll Institute for Extractive Metallurgy, Mining Engineering Department \& George S. Ansell Department of \\ Metallurgical and Materials Engineering, Colorado School of Mines, Golden, CO 80401, USA; \\ jtrouba@mymail.mines.edu (J.T.); cgandersmines@gmail.com (C.A.) \\ 2 Rio Tinto Kennecott Utah Copper, Magna, UT 84944, USA; Shijie.Wang@riotinto.com \\ * Correspondence: mcaplan@mymail.mines.edu; Tel.: +1-(281)-300-2619
}

Citation: Caplan, M.; Trouba, J.;

Anderson, C.; Wang, S.

Hydrometallurgical Leaching of

Copper Flash Furnace Electrostatic Precipitator Dust for the Separation of Copper from Bismuth and Arsenic. Metals 2021, 11, 371. https:// doi.org/10.3390/met11020371

Academic Editor: Srecko Stopic

Received: 13 January 2021

Accepted: 19 February 2021

Published: 23 February 2021

Publisher's Note: MDPI stays neutral with regard to jurisdictional claims in published maps and institutional affiliations.

Copyright: (c) 2021 by the authors. Licensee MDPI, Basel, Switzerland. This article is an open access article distributed under the terms and conditions of the Creative Commons Attribution (CC BY) license (https:// creativecommons.org/licenses/by/ $4.0 /)$.

\begin{abstract}
Flash furnace electrostatic precipitator dust (FF-ESP dust) is a recycle stream in some primary copper production facilities. This dust contains high amounts of copper. In some cases, the FF-ESP dust contains elevated levels of bismuth and arsenic, both of which cause problems during the electrorefining stages of copper production. Because of this, methods for separation of copper from bismuth and arsenic in FF-ESP dust are necessary. Hydrometallurgical leaching using a number of lixiviants, including sulfuric acid, sulfurous acid, sodium hydroxide, and water, were explored. Pourbaix diagrams of copper, bismuth, and arsenic were used to determine sets of conditions which would thermodynamically separate copper from bismuth and arsenic. The data indicate that water provides the best overall separation between copper and both bismuth and arsenic. Sodium hydroxide provided a separation between copper and arsenic. Sulfurous acid provided a separation between copper and bismuth. Sulfuric acid did not provide any separations between copper and bismuth or copper and arsenic.
\end{abstract}

Keywords: copper processing; copper leaching; copper bearing dusts

\section{Introduction}

Rio Tinto Kennecott Copper (RTKC) is a primary copper producer based in Utah, U.S. Like many primary copper producers, RTKC utilizes a flash smelting stage in their process [1]. During the flash smelting process, a portion of the input material is captured, as a dust, by the gases generated by the smelting reactions [2-4]. These gases must be processed prior to release in order to meet regulatory emissions requirements. One of the unit operations necessary for gas treatment is to separate the solid dust from the gases. This is accomplished using a waste heat boiler and an electrostatic precipitator (ESP) [4]. The separated material from the ESP is referred to as the flash furnace electrostatic precipitator dust (FF-ESP dust).

The copper content of the FF-ESP dust is high, over $20 \%$ by mass. Because of this, it is necessary to reprocess this material for its copper. Commonly, this is done by simply recycling the FF-ESP dust back into the flash furnace. However, in the case of RTKC, the dust contains high concentrations of both bismuth and arsenic, both of which cause problems further downstream in the copper production process and the final copper product [5].

In metallic copper, arsenic introduces a number of detrimental qualities. It reduces conductivity; increases recrystallization temperature, which may result in increased processing costs if annealing is necessary; and causes grain boundary cracking [6]. In the case of bismuth impurity in copper, bismuth causes embrittlement and increases the work hardening rate [6]. This is because bismuth has no practical solubility in copper and therefore 
segregates to the copper grain boundaries. In some conditions this can result in liquid metal embrittlement and/or grain boundary wetting. Because of these detriments, the chemical specification for most high-quality cathode coppers, including LME Grade A Cathode Copper, follows ASTM B115-10 Grade 1, which limits arsenic content to 5 ppm and bismuth content to 1.0 ppm [7].

Regarding processing, bismuth and arsenic cause anode passivation and reductions in current efficiency [8]. This is especially true of bismuth. Because of this, the FF-ESP dust cannot always be recycled, resulting in otherwise unnecessary copper losses. Additionally, FF-ESP dust is considered a hazardous waste by U.S. regulatory agencies (in large part due to arsenic), and therefore, the inability to process it results in increased waste stream costs [9]. Alternative methods for FF-ESP dust processing, especially methods that separate copper from bismuth and arsenic, are necessary. That said, any process that deals with the RTKC FF-ESP dust must deal with the arsenic present in it. Generally, this is done via fixation and is well understood in the industry $[9,10]$.

Hydrometallurgical leaching is a commonly used method for the selective separation of one or more elements or compounds. A number of papers have reported on the efficacy of leaching copper flue dusts using sulfuric acid in order to recover copper and other metals; however, separations between copper and bismuth or arsenic are not common [11,12]. Copper flue dusts commonly contain water-soluble copper sulfates; because of this, water is also used to recover copper from copper flue dusts. $[4,12]$ Ha et al. have shown that bismuth can be leached from copper flue dusts using sulfuric acid and sodium hydroxide, but copper is also leached during this process [13].

The potential for hydrometallurgical selectivity and separations can be exhibited by Pourbaix diagrams. These diagrams depict electro-potential and $\mathrm{pH}$ on the axes and show the regions of thermodynamic stability for known species of a given system.

Figure 1 shows overlaid copper and bismuth Pourbaix diagrams. This provides regions where separation between copper and bismuth is theoretically possible. The same is shown in Figure 2 but for copper and arsenic instead. All Pourbaix diagrams were generated using StabCal software at $25^{\circ} \mathrm{C}$, and molarities are as stated in the captions.

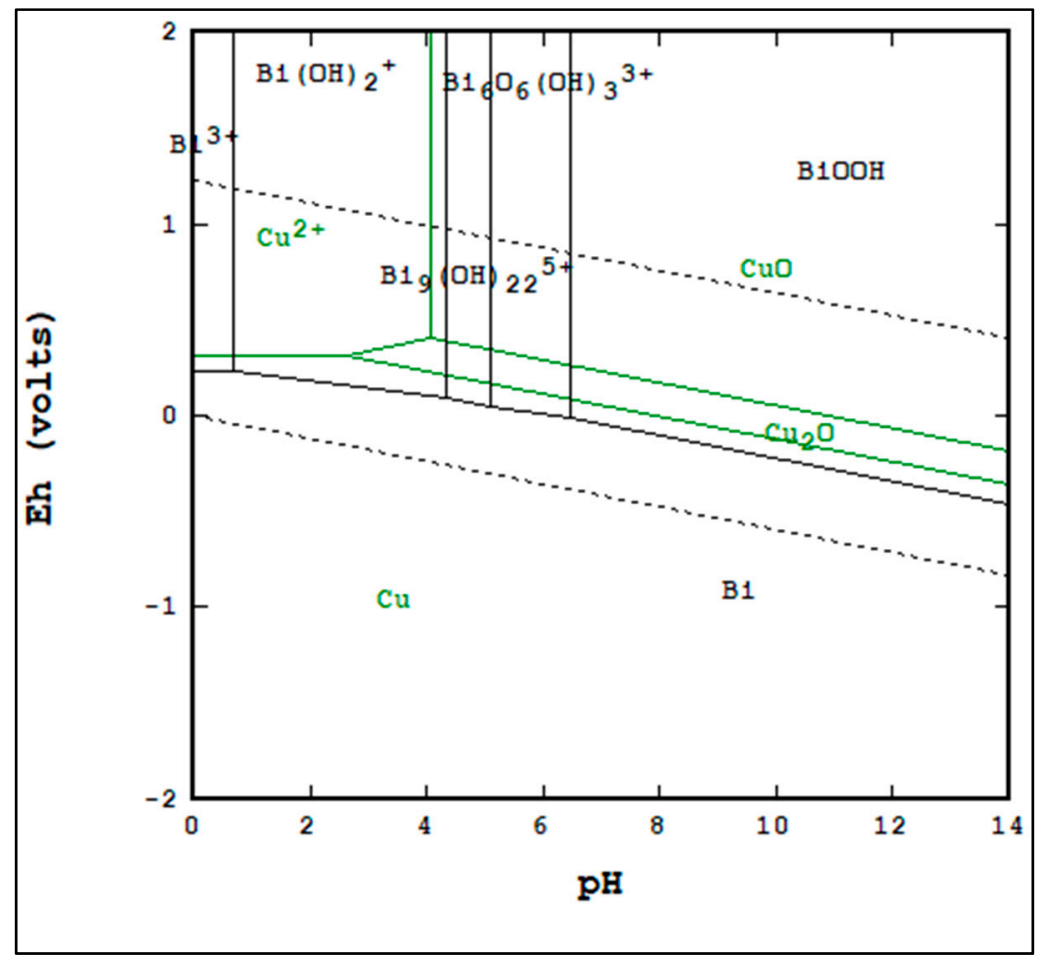

Figure 1. Copper (0.173 M) and bismuth (0.00178 M) Pourbaix diagram overlay. 


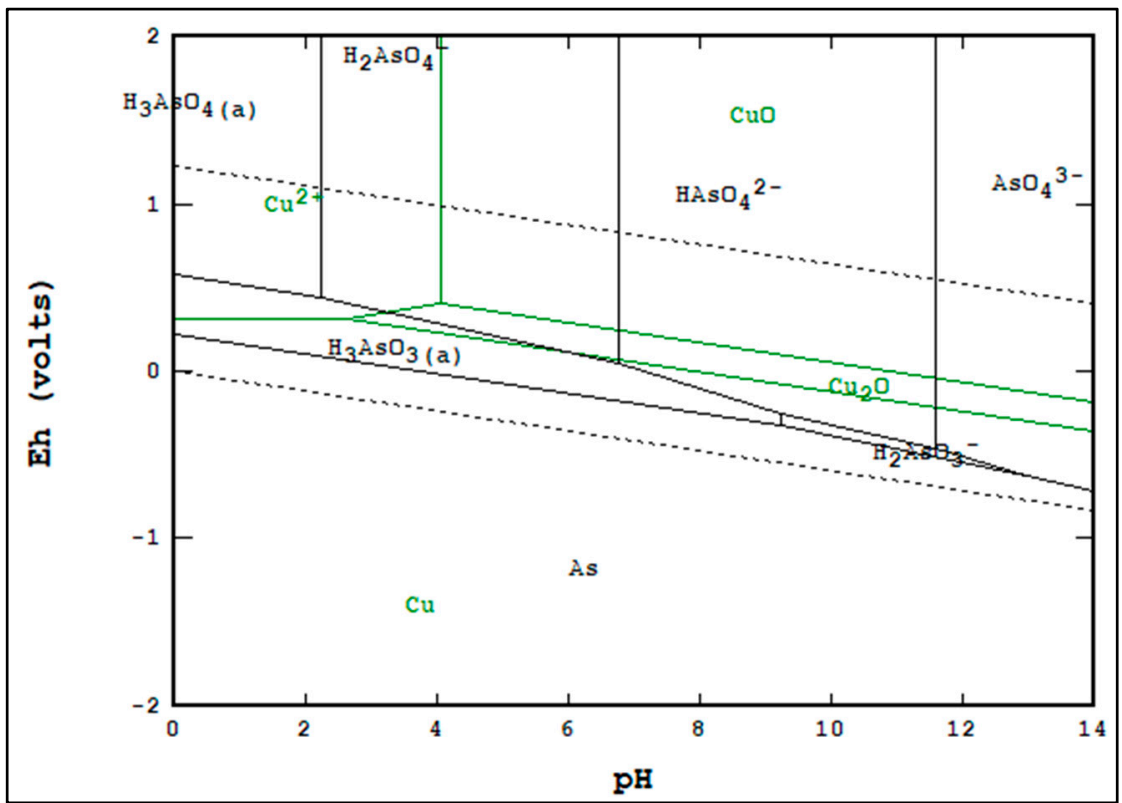

Figure 2. Copper $(0.173 \mathrm{M})$ and $\operatorname{arsenic}(0.0320 \mathrm{M})$ Pourbaix diagram overlay.

As shown in this paper, the majority of the RTKC dust is composed of mixed amorphous oxide phases containing the copper, bismuth, and arsenic. Ideally, Pourbaix diagrams are generated using the actual phases present in the system. That said, the phase chemistry and population of the dust is complex and not easily simulated. Because of this, the Pourbaix diagrams used are for pure, ideal phases, and therefore they cannot be used to predict exactly what conditions will provide the thermodynamic possibility for separation, but they can be used as a viable starting point.

From Figure 1, it can be seen that it is thermodynamically possible to separate copper and bismuth in the regions of overlap between $\mathrm{Bi}(\mathrm{OH})_{2}^{+}$and $\mathrm{CuO}$ or $\mathrm{Cu}_{2} \mathrm{O}$. From Figure 2, it can be seen that it is thermodynamically possible to separate copper and arsenic in the regions of overlap between $\mathrm{HAsO}_{4}^{2-}$ or $\mathrm{AsO}_{4}^{3-}$ and $\mathrm{CuO}$ or $\mathrm{Cu}_{2} \mathrm{O}$. By contrasting both figures, it can be seen that it is not thermodynamically likely to separate copper from both arsenic and bismuth in a single leaching stage.

Shown in Figure 3 is a copper Pourbaix diagram with concentration on the vertical axis. Soluble regions are "filled in". It can be seen that as copper concentration increases, so too does the portion of regions that are insoluble. Figure 4 shows the same diagram but for bismuth. The bismuth diagram exhibits the same pattern as copper. Shown in Figure 5 is the 3D arsenic Pourbaix diagram. Unlike copper and bismuth, arsenic solubility increases with arsenic concentration.

Dust processing in general is well suited to hydrometallurgical processing for two primary reasons: the innate ability for hydrometallurgy to be selective, and the environmental benefit of eliminating the emission of toxic metals in gaseous form [14]. Historically, hydrometallurgical developments have enabled high separability and selectivity, such as in the Sherritt Gordon process for the separation and recovery of cobalt, nickel, and copper [15], as well as in the Merrill Crowe cyanidation process for the recovery of gold [14].

In the specific case of copper smelter dusts, a number of studies have been published involving efforts to separate copper from arsenic and bismuth. Ichimura et al., Kovyazin et al., Yang et al., Shanazi et al., and Chen et al. have published studies showing separation of copper from arsenic and/or bismuth via first leaching all three metals and then separating copper from bismuth and arsenic via precipitation methodology [16-19]. 


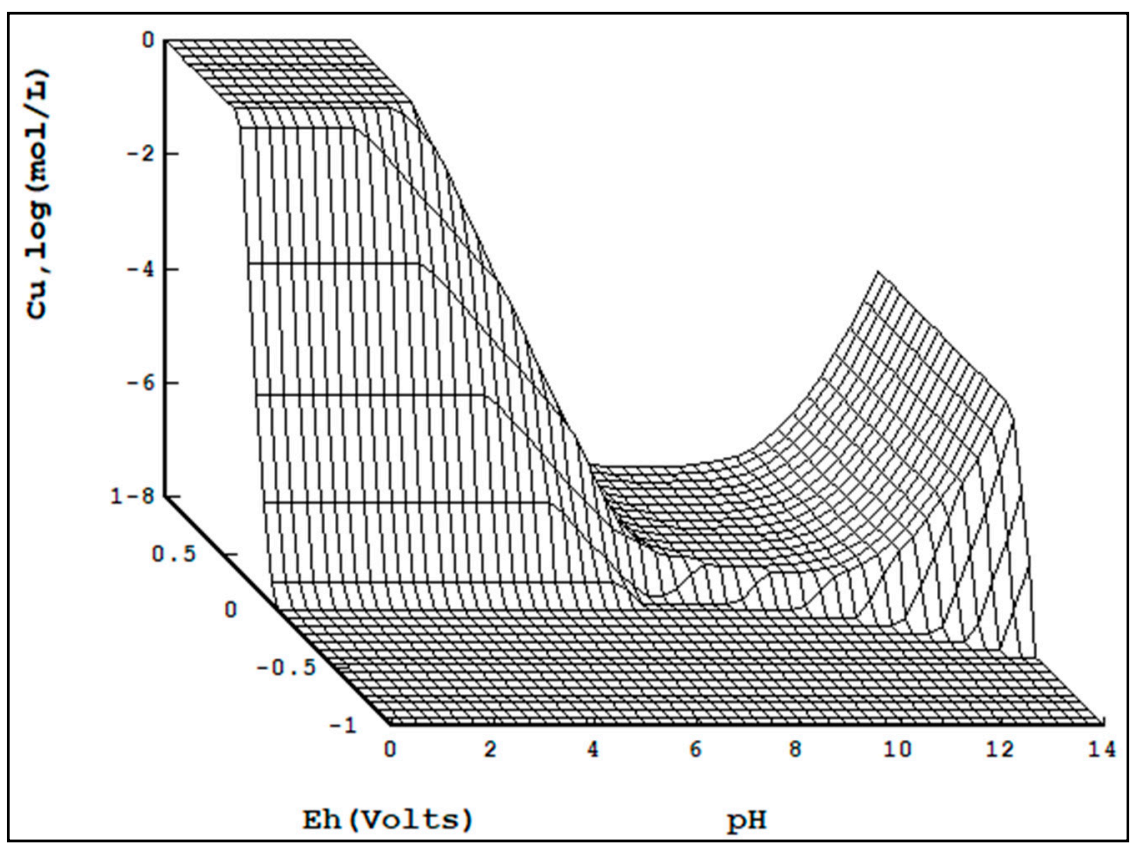

Figure 3. 3D Cu Pourbaix diagram.

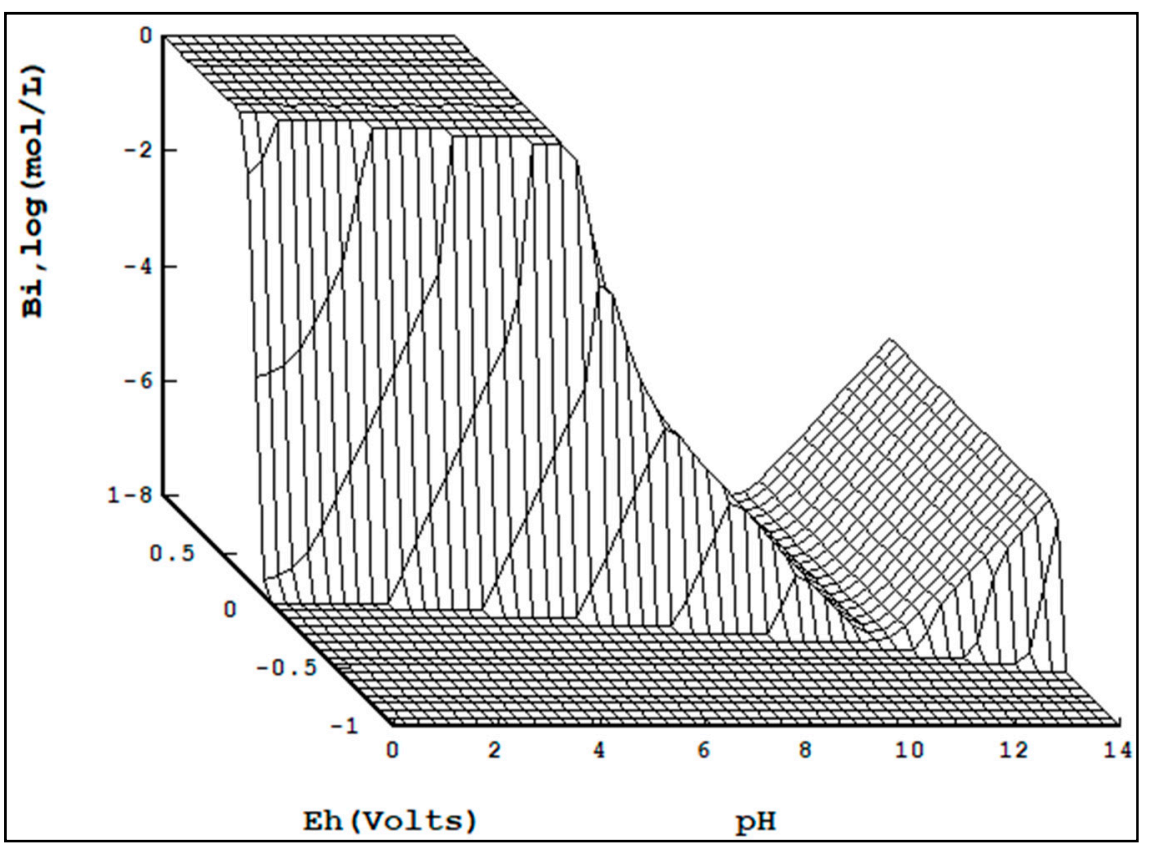

Figure 4. 3D Bi Pourbaix diagram.

This work aims to determine the efficacy of utilizing various hydrometallurgical leaching lixiviants for separating copper from bismuth and arsenic in RTKC FF-ESP dust without a precipitation stage. The lixiviants investigated were sulfuric acid, sulfurous acid, sodium hydroxide, and water. Sulfuric acid is commonly used to recover copper from copper smelter flue dusts and is known to leach arsenic and bismuth as well [19-21]. In this study, it was used to provide a baseline of sorts for recovery. Sulfurous acid was used as it provides similar, but more reductive, conditions compared to sulfuric acid. Li et al. and Guo et al. have shown that alkaline leaching methodologies can be used to recovery arsenic from arsenic-bearing metallurgical dusts [22,23]. Zhang et al. has shown that arsenic can be selectively separated from copper using alkali leaching [21]. Sodium hydroxide was used to confirm the efficacy of alkaline leaching for the separation of arsenic 
in the unique chemistry of the RTKC dust. Morales et al. has shown that water can provide at least a partial separation between arsenic and copper; because of this, water was used to determine the efficacy of leaching in neutral environments [12].

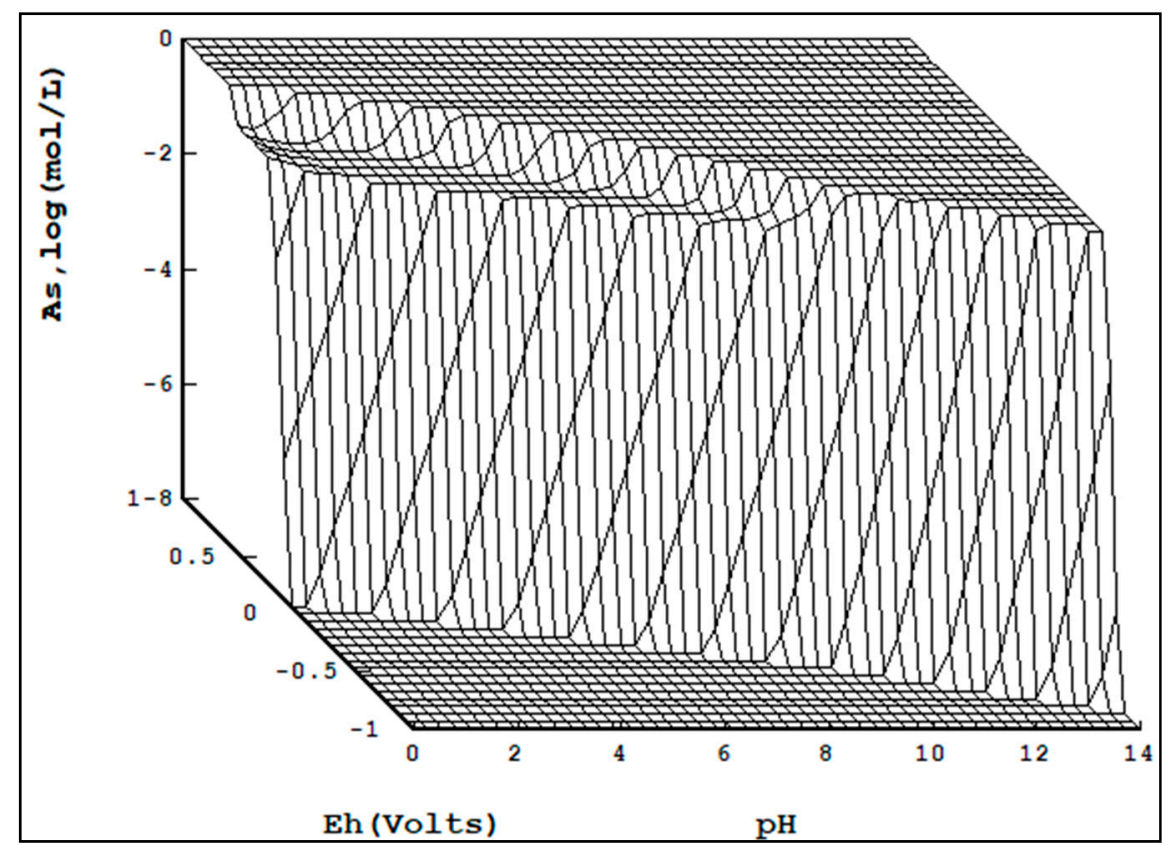

Figure 5. 3D As Pourbaix diagram.

An initial satisfactory separation would occur if copper was transferred to the leachate, with bismuth and arsenic remaining in the residue, or the opposite, with copper in the residue and both bismuth and arsenic in the leachate.

\section{Materials and Methods}

FF-ESP dust was acquired from RTKC and analyzed for copper, bismuth, and arsenic content using inductively coupled plasma mass spectroscopy (ICP-MS). The ICP-MS results are shown in Table 1. By mass, over $20 \%$ of the dust is composed of copper, approximately $5 \%$ of the dust is arsenic, and the bismuth concentration is over $7000 \mathrm{ppm}$. As stated, the concentrations of the arsenic and bismuth are unacceptably high and therefore must be separated from the copper in order for non-problematic electrorefining.

Table 1. Concentration (by mass) of $\mathrm{Cu}, \mathrm{Bi}$, and As in FF-ESP dust.

\begin{tabular}{cccc}
\hline Element & Copper & Bismuth & Arsenic \\
\hline Concentration & 21.99 & 7443 & 4.80 \\
\hline Unit & Mass $\%$ & ppm & Mass $\%$ \\
\hline
\end{tabular}

In addition to the ICP-MS analysis above, AMICS automated mineralogy was utilized to determine the overall phase composition of the FF-ESP dust. The AMICS work was performed by Eagle Engineering. Table 2 lists the identified phases as well as their fraction of the dust by mass. Figure 6 is an AMICS image, and Table 3 provides a color key for Figure 6. From these, it can be seen that the majority of the dust is composed of mixed amorphous phases containing copper, iron, silicon, and arsenic. Because arsenic and copper are consistently present in the same phases, it is impossible to separate them with physical methods; chemical methods, such as hydrometallurgical leaching, are necessary. 
Table 2. AMICS phase composition of FF-ESP dust.

\begin{tabular}{ccc}
\hline Mineral & Chemistry & Mass \% \\
\hline Barite & $\mathrm{BaSO}_{4}$ & 0.03 \\
\hline Phase 1 & $\mathrm{Cu}_{0.23} \mathrm{Fe}_{0.24} \mathrm{Si}_{0.03} \mathrm{~S}_{0.07} \mathrm{As}_{0.12} \mathrm{O}_{0.30}$ & 22.67 \\
\hline Phase 2 & $\mathrm{Cu}_{0.19} \mathrm{Fe}_{0.12} \mathrm{Si}_{0.18} \mathrm{~S}_{0.01} \mathrm{As}_{0.04} \mathrm{O}_{0.38} \mathrm{Al}_{0.07}$ & 5.81 \\
\hline CuFeSiO 4 & $\mathrm{Cu}_{0.30} \mathrm{Fe}_{0.26} \mathrm{Si}_{0.13} \mathrm{O}_{0.31}$ & 3.67 \\
\hline CuFeZnO & $\mathrm{Cu}_{0.25} \mathrm{Fe}_{0.22} \mathrm{Zn}_{0.26} \mathrm{O}_{0.27}$ & 5.65 \\
\hline Phase 4 & $\mathrm{Cu}_{0.22} \mathrm{Fe}_{0.47} \mathrm{~S}_{0.02} \mathrm{O}_{0.29}$ & 24.42 \\
\hline Phase 5 & $\mathrm{Cu}_{0.16} \mathrm{Fe}_{0.10} \mathrm{Si}_{0.14} \mathrm{~S}_{0.12} \mathrm{As}_{0.04} \mathrm{O}_{0.44}$ & 11.40 \\
\hline Phase 6 & $\mathrm{Cu}_{0.32} \mathrm{Fe}_{0.06} \mathrm{Si}_{0.20} \mathrm{~S}_{0.02} \mathrm{As}_{0.06} \mathrm{O}_{0.32}$ & 3.93 \\
\hline Phase 7 & $\mathrm{Cu}_{0.39} \mathrm{Fe}_{0.22} \mathrm{Si}_{0.02} \mathrm{~S}_{0.03} \mathrm{As}_{0.12} \mathrm{O}_{0.24}$ & 1.51 \\
\hline Phase 8 & $\mathrm{Cu}_{0.21} \mathrm{Fe}_{0.32} \mathrm{Si}_{0.04} \mathrm{~S}_{0.04} \mathrm{As}_{0.09} \mathrm{O}_{0.30}$ & 13.04 \\
\hline Phase 9 & $\mathrm{Cu}_{0.22} \mathrm{Fe}_{0.23} \mathrm{Si}_{0.07} \mathrm{~S}_{0.03} \mathrm{As}_{0.11} \mathrm{O}_{0.31}$ & 7.85 \\
\hline Quartz & $\mathrm{SiO}_{2}$ \\
\hline
\end{tabular}

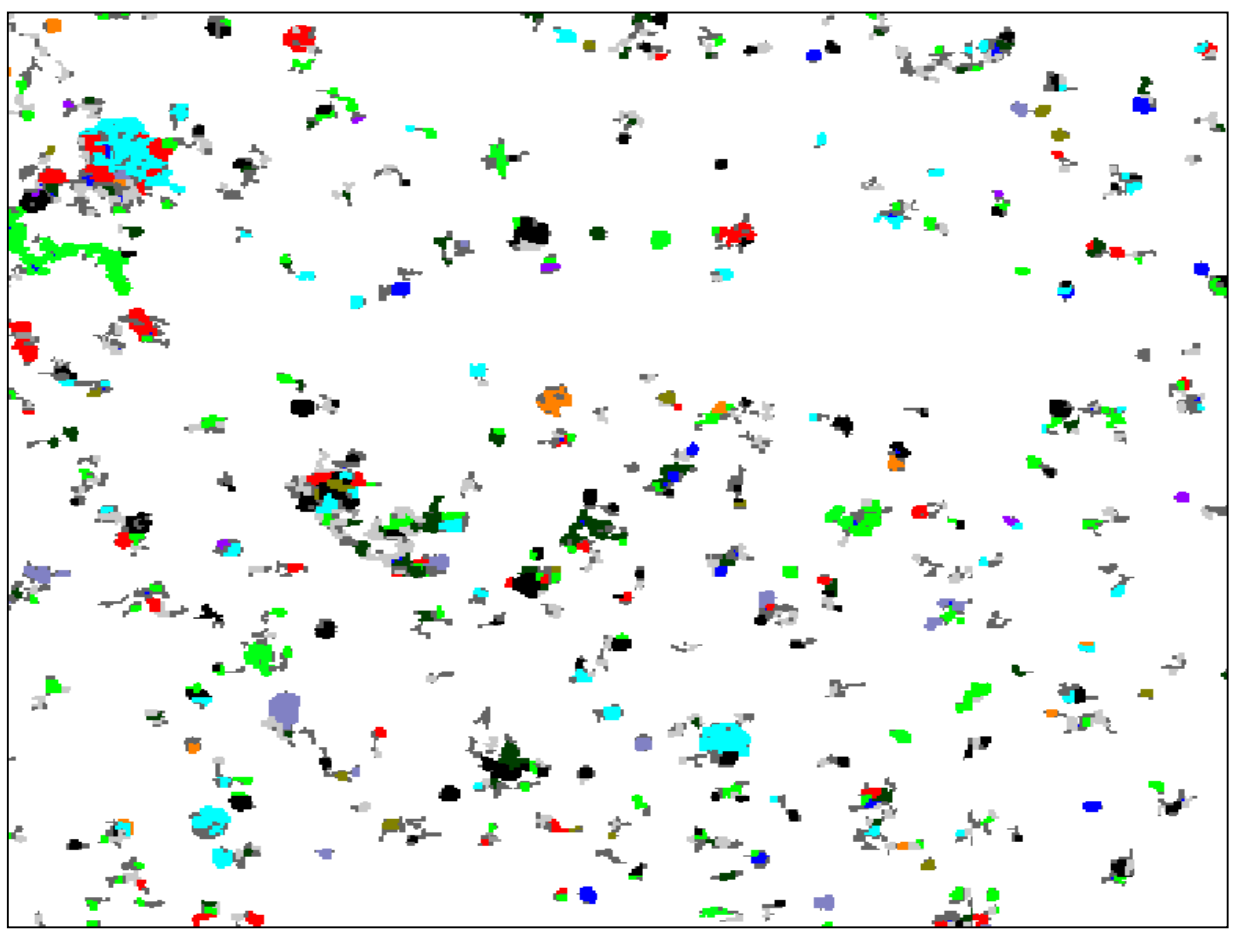

Figure 6. AMICS image of FF-ESP dust.

Table 3. AMICS color key.

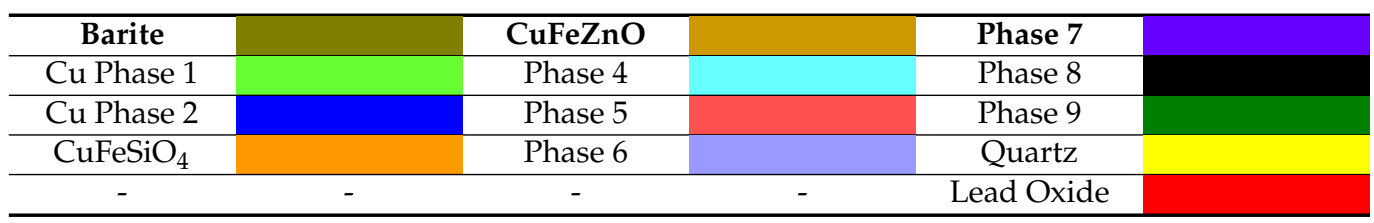

Table 4 shows the AMICS elemental composition for the FF-ESP dust. When compared to the ICP-MS composition data, there is good agreement between the two for copper and arsenic. The bismuth concentration shown in Table 1 is below the detection limit of AMICS and would not show up in the scan. Given that AMICS composition data are considered "semi-quantitative", only ICP-MS composition data are used for calculations. 
Table 4. AMICS elemental composition data for FF-ESP dust.

\begin{tabular}{cc}
\hline Element & Mass \% \\
\hline Barium & 0.02 \\
\hline Oxygen & 35.16 \\
\hline Copper & 20.10 \\
\hline Iron & 27.66 \\
\hline Silicon & 5.40 \\
\hline Sulfur & 4.68 \\
\hline Arsenic & 5.24 \\
\hline Aluminum & 0.41 \\
\hline Zinc & 1.32 \\
\hline
\end{tabular}

A $1 \mathrm{~L}$ solution containing the requisite concentration of the appropriate lixiviant (ACS grade or higher) was created using deionized water and the lixiviant. This solution was then placed into a baffled flask, heated using a hot plate, and agitated using a magnetic stir bar. The temperature of this solution was measured and controlled via a glass-coated thermocouple. Once the solution reached the appropriate temperature, 50 grams of the FF-ESP dust were added. Upon completion of the leaching time, the leach liquor was separated from the residue using filtration.

The testing conditions for each sulfuric acid, sulfurous acid, caustic, and water design matrix are shown in Table 5, Table 6, Table 7, and Table 8, respectively. The trial conditions for each matrix were generated using Design-Expert 12 software.

Table 5. Test conditions for sulfuric acid trials.

\begin{tabular}{cccc}
\hline Trial & Time (h) & Temperature $\left({ }^{\circ} \mathrm{C}\right)$ & $\mathbf{H}_{\mathbf{2}} \mathbf{S O}_{\mathbf{4}}(\mathbf{m L} / \mathrm{L})$ \\
\hline 1 & 0.5 & 50 & 50 \\
\hline 2 & 2 & 50 & 25 \\
\hline 3 & 0.5 & 90 & 25 \\
\hline 4 & 2 & 90 & 50 \\
\hline 5 & 1.25 & 70 & 37.5 \\
\hline 6 & 1.25 & 70 & 37.5 \\
\hline 7 & 0.5 & 50 & 200 \\
\hline 8 & 2 & 90 & 100 \\
\hline
\end{tabular}

Table 6. Test conditions for sulfurous acid trials.

\begin{tabular}{cccc}
\hline Trial & Time (h) & Temperature $\left({ }^{\circ} \mathbf{C}\right)$ & $\mathbf{H}_{\mathbf{2}} \mathbf{S O}_{3}(\mathbf{m L} / \mathrm{L})$ \\
\hline 1 & 0.5 & 50 & 50 \\
\hline 2 & 2 & 50 & 25 \\
\hline 3 & 0.5 & 90 & 25 \\
\hline 4 & 2 & 90 & 50 \\
\hline 5 & 1.25 & 70 & 37.5 \\
\hline 6 & 1.25 & 70 & 37.5 \\
\hline 7 & 0.5 & 50 & 150 \\
\hline 8 & 2 & 90 & 150 \\
\hline
\end{tabular}


Table 7. Test conditions for caustic trials.

\begin{tabular}{cccc}
\hline Trial & Time (h) & Temperature $\left({ }^{\circ} \mathbf{C}\right)$ & NaOH (g/L) \\
\hline 1 & 0.5 & 50 & 50 \\
\hline 2 & 2 & 50 & 5 \\
\hline 3 & 0.5 & 90 & 5 \\
\hline 4 & 2 & 90 & 50 \\
\hline 5 & 1.25 & 70 & 27.5 \\
\hline 6 & 1.25 & 70 & 27.5 \\
\hline 7 & 24 & 70 & 30 \\
\hline
\end{tabular}

Table 8. Test conditions for water trials.

\begin{tabular}{ccc}
\hline Trial & Time (h) & Temperature $\left({ }^{\circ} \mathbf{C}\right)$ \\
\hline 1 & 0.5 & 25 \\
\hline 2 & 2 & 25 \\
\hline 3 & 0.5 & 90 \\
\hline 4 & 2 & 90 \\
\hline 5 & 1.25 & 65 \\
\hline 6 & 1.25 & 57.5 \\
\hline 7 & 1.5 & 75
\end{tabular}

Analysis of the leach liquors was done via atomic absorption spectroscopy (AAS) and ICP-MS. A statistical analysis of the data was completed using Design-Expert 12 software.

\section{Results}

The recoveries of each element to the leachates, as well as the starting $\mathrm{pH}$, ending $\mathrm{pH}$ and ending Eh values, are shown in Table 9 (the sulfuric acid trials), Table 10 (the sulfurous acid trials), Table 11 (the caustic trials), and Table 12 (the water trials). The starting $\mathrm{pH}$ values were calculated using first principles, and random trials were confirmed using titration. The ending $\mathrm{pH}$ values were determined via titration. The ending Eh values were determined via Eh probe with a standard hydrogen electrode as reference. The recovery $(R)$ of each element (i) was calculated using the concentration of $i$ in the leachate and FF-ESP dust, the volume (V) of the leachate, and the mass $(\mathrm{M})$ of the dust sample used, as shown in Equation (1).

$$
\% \text { Recovery for element } \mathrm{i}: \% \mathrm{R}_{\mathrm{i}}=100 \times\left(\left[\mathrm{i}_{\text {leachate }}\right] \times \mathrm{V}\right) /\left(\left[\mathrm{i}_{\text {FF-ESP Dust }}\right] \times \mathrm{M}\right)
$$


Table 9. Elemental recoveries (\%) to leachates of sulfuric acid trials, $\mathrm{pH}$ data, and Eh data.

\begin{tabular}{|c|c|c|c|c|c|c|c|c|c|}
\hline \multirow{2}{*}{ Trial } & \multirow{2}{*}{ Time (h) } & \multirow{2}{*}{$\begin{array}{c}\text { Temperature } \\
\left({ }^{\circ} \mathrm{C}\right)\end{array}$} & \multirow{2}{*}{$\begin{array}{l}\mathrm{H}_{2} \mathrm{SO}_{4} \\
(\mathrm{~mL} / \mathrm{L})\end{array}$} & \multicolumn{3}{|c|}{ \% Recovery } & \multirow{2}{*}{ Starting $\mathrm{pH}$} & \multirow{2}{*}{ Ending $\mathrm{pH}$} & \multirow{2}{*}{ Ending Eh (mV) } \\
\hline & & & & Copper & Bismuth & Arsenic & & & \\
\hline 1 & 0.5 & 50 & 50 & 76.4 & 44.05 & 61.81 & -0.26 & 0.59 & 461.3 \\
\hline 2 & 2 & 50 & 25 & 77.21 & 38.76 & 51.71 & 0.04 & 0.68 & 454.8 \\
\hline 3 & 0.5 & 90 & 25 & 84.49 & 42.73 & 56.82 & 0.04 & 0.71 & 451 \\
\hline 4 & 2 & 90 & 50 & 85.27 & 48.46 & 71.28 & -0.26 & 0.51 & 454.7 \\
\hline 5 & 1.25 & 70 & 37.5 & 83.48 & 44.36 & 69.03 & -0.14 & 0.58 & 459.3 \\
\hline 6 & 1.25 & 70 & 37.5 & 82.29 & 45.06 & 65.00 & -0.14 & 0.6 & 459.2 \\
\hline 7 & 0.5 & 50 & 200 & 77.25 & 32.23 & 60.45 & -0.87 & 0.32 & 461.8 \\
\hline 8 & 2 & 90 & 100 & 89.85 & 44.23 & 64.12 & -0.57 & 0.49 & 460.4 \\
\hline
\end{tabular}

Table 10. Elemental recoveries (\%) to leachates of sulfurous acid trials, $\mathrm{pH}$ data, and Eh data.

\begin{tabular}{|c|c|c|c|c|c|c|c|c|c|}
\hline \multirow{2}{*}{ Trial } & \multirow{2}{*}{ Time (h) } & \multirow{2}{*}{$\begin{array}{l}\text { Temperature } \\
\left({ }^{\circ} \mathrm{C}\right)\end{array}$} & \multirow{2}{*}{$\begin{array}{r}\mathrm{H}_{2} \mathrm{SO}_{3} \\
(\mathrm{~mL} / \mathrm{L})\end{array}$} & \multicolumn{3}{|c|}{ \% Recovery } & \multirow{2}{*}{ Starting pH } & \multirow{2}{*}{ Ending $\mathrm{pH}$} & \multirow{2}{*}{ Ending Eh (mV) } \\
\hline & & & & Copper & Bismuth & Arsenic & & & \\
\hline 1 & 0.5 & 50 & 50 & 70.42 & 1.03 & 25.84 & 0.17 & 1.8 & 263.1 \\
\hline 2 & 2 & 50 & 25 & 69.31 & 0.21 & 25.03 & 0.47 & 2.03 & 326.2 \\
\hline 3 & 0.5 & 90 & 25 & 71.41 & 4.26 & 26.25 & 0.47 & 2.09 & 321.1 \\
\hline 4 & 2 & 90 & 50 & 76.84 & 4.65 & 30.81 & 0.17 & 2.02 & 331.4 \\
\hline 5 & 1.25 & 70 & 37.5 & 71.12 & 3.28 & 29.15 & 0.29 & 2.14 & 318.9 \\
\hline 6 & 1.25 & 70 & 37.5 & 70.64 & 2.59 & 27.93 & 0.29 & 2.13 & 298.6 \\
\hline 7 & 0.5 & 50 & 150 & 74.78 & 1.81 & 29.63 & -0.31 & 1.92 & 278.4 \\
\hline 8 & 2 & 90 & 150 & 81.75 & 3.02 & 56.26 & -0.31 & 1.9 & 269.8 \\
\hline
\end{tabular}

Table 11. Elemental recoveries (\%) to leachates of caustic trials, $\mathrm{pH}$ data, and Eh data.

\begin{tabular}{|c|c|c|c|c|c|c|c|c|c|}
\hline \multirow{2}{*}{ Trial } & \multirow{2}{*}{ Time (h) } & \multirow{2}{*}{$\begin{array}{c}\text { Temperature } \\
\left({ }^{\circ} \mathrm{C}\right)\end{array}$} & \multirow{2}{*}{$\begin{array}{c}\mathrm{NaOH} \\
(\mathrm{g} / \mathrm{L})\end{array}$} & \multicolumn{3}{|c|}{ \% Recovery } & \multirow{2}{*}{ Starting $\mathrm{pH}$} & \multirow{2}{*}{ Ending pH } & \multirow{2}{*}{ Ending Eh $(\mathrm{mV})$} \\
\hline & & & & Copper & Bismuth & Arsenic & & & \\
\hline 1 & 0.5 & 50 & 50 & 0.25 & 0.07 & 27.94 & 14.1 & 12.95 & -32.1 \\
\hline 2 & 2 & 50 & 5 & 43.13 & 0.01 & 0.04 & 13.1 & 4.14 & 231.8 \\
\hline 3 & 0.5 & 90 & 5 & 43.4 & 0.01 & 1.76 & 13.1 & 3.68 & 280.1 \\
\hline 4 & 2 & 90 & 50 & 0.46 & 0.04 & 63.08 & 14.1 & 13.11 & -33.8 \\
\hline 5 & 1.25 & 70 & 27.5 & 0.09 & 0.02 & 30.13 & 13.84 & 12.79 & 25.2 \\
\hline 6 & 1.25 & 70 & 27.5 & 0.09 & 0.01 & 25.63 & 13.84 & 12.81 & -22.4 \\
\hline 7 & 24 & 70 & 30 & 0.35 & 0.01 & 45.21 & 13.88 & 12.7 & 31.2 \\
\hline
\end{tabular}


Table 12. Elemental recoveries (\%) to leachates of water trials, $\mathrm{pH}$ data, and Eh data.

\begin{tabular}{|c|c|c|c|c|c|c|c|c|}
\hline \multirow{2}{*}{ Trial } & \multirow{2}{*}{ Time (h) } & \multirow{2}{*}{$\begin{array}{c}\text { Temperature } \\
\left({ }^{\circ} \mathrm{C}\right)\end{array}$} & \multicolumn{3}{|c|}{ \% Recovery } & \multirow{2}{*}{ Starting $\mathrm{pH}$} & \multirow{2}{*}{ Ending pH } & \multirow{2}{*}{ Ending Eh $(\mathrm{mV})$} \\
\hline & & & Copper & Bismuth & Arsenic & & & \\
\hline 1 & 0.5 & 25 & 64.14 & 0.17 & 7.86 & 7 & 1.8 & 435.6 \\
\hline 2 & 2 & 25 & 66.64 & 0.14 & 7.2 & 7 & 1.89 & 436.1 \\
\hline 3 & 0.5 & 90 & 66.57 & 0.05 & 4.86 & 7 & 1.67 & 435.2 \\
\hline 4 & 2 & 90 & 66.35 & 0.03 & 5.69 & 7 & 1.64 & 435.7 \\
\hline 5 & 1.25 & 65 & 65.61 & 0.04 & 5.4 & 7 & 1.76 & 433.9 \\
\hline 6 & 1.25 & 57.5 & 64.89 & 0.03 & 5.67 & 7 & 1.79 & 433.8 \\
\hline 7 & 1.5 & 75 & 68.69 & 0.13 & 5.33 & 7 & 2.06 & 400.8 \\
\hline
\end{tabular}

\section{Discussion}

Given that copper is the primary product of RTKC, either a high or a low copper recovery to the leachate is desired. This allows for the majority of the copper to be processed from either the leachate or residue. By comparing the recovery values shown above, it can be seen that sulfuric acid provides the highest copper recovery to the leachate. Unfortunately, sulfuric acid did not provide a separation between copper and either bismuth or arsenic.

Sodium hydroxide provided the lowest copper recovery to the leachate, leaving over $99 \%$ of the copper in the residue in all but the low alkalinity trials. Like sulfuric acid, caustic leaching did not provide a separation between copper and bismuth. That said, trial 4 of the caustic leach matrix did provide a moderate separation between copper and arsenic. It provided essentially no copper recovery and a $63 \%$ arsenic recovery. That said, higher arsenic recoveries were expected based on existing studies on alkaline leaching of arsenic in metallurgical dusts, which have shown arsenic recoveries of over $90 \%$ at the highest as well as many trials with recoveries over $80 \%$ [22,23]. The difference in arsenic recovery may be attributed to the exact type of alkaline leaching used, as the referenced studies utilized either pressure $\mathrm{NaOH}$ leaching or $\mathrm{NaOH}-\mathrm{Na}_{2} \mathrm{~S}$ leaching, or may simply be due to the difference in the materials leached.

By comparing trial 4 to the other alkaline trials, it becomes apparent that higher alkalinities, higher temperature, and longer leach times provide higher arsenic recovery without increases in recovery of copper or bismuth. This is partially supported by the response surfaces for caustic leaching (below) generated using Design-Expert 12.

It should be noted that caustic trials 2 and 3, which were only slightly alkaline relative to the other caustic trials, were the only caustic trials to leach a non-near-zero amount of copper. It is hypothesized that the sulfur in the FF-ESP dust reacts with water when leached and generates sulfuric acid. The acid then dissolves the copper present in the dust, resulting in the higher copper recoveries. This is supported by the $\mathrm{pH}$ data associated with caustic trials 2 and 3, which show that the leach solution ends substantially more acidic than it starts, and the $\mathrm{pH}$ data associated with the water leach trials, which show the same pattern. It is believed that the other caustic trials generated sulfuric acid, but that the generated acid was reacted with the sodium hydroxide before it was able to dissolve copper, and thus the lack of a large shift in $\mathrm{pH}$.

Figure 7 shows copper recovery response surfaces from the caustic leaching design matrix at the minimum and maximum sodium hydroxide concentrations tested. Both surfaces indicate that time and temperature have no meaningful effect on copper recovery, but that sodium hydroxide concentration does. The surfaces indicate that at low sodium hydroxide concentrations (approximately $5 \mathrm{~g} / \mathrm{L}$ ) over $30 \%$ of the copper can be recovered, and that at higher sodium hydroxide concentrations, copper recovery can be reduced to almost $0 \%$. 

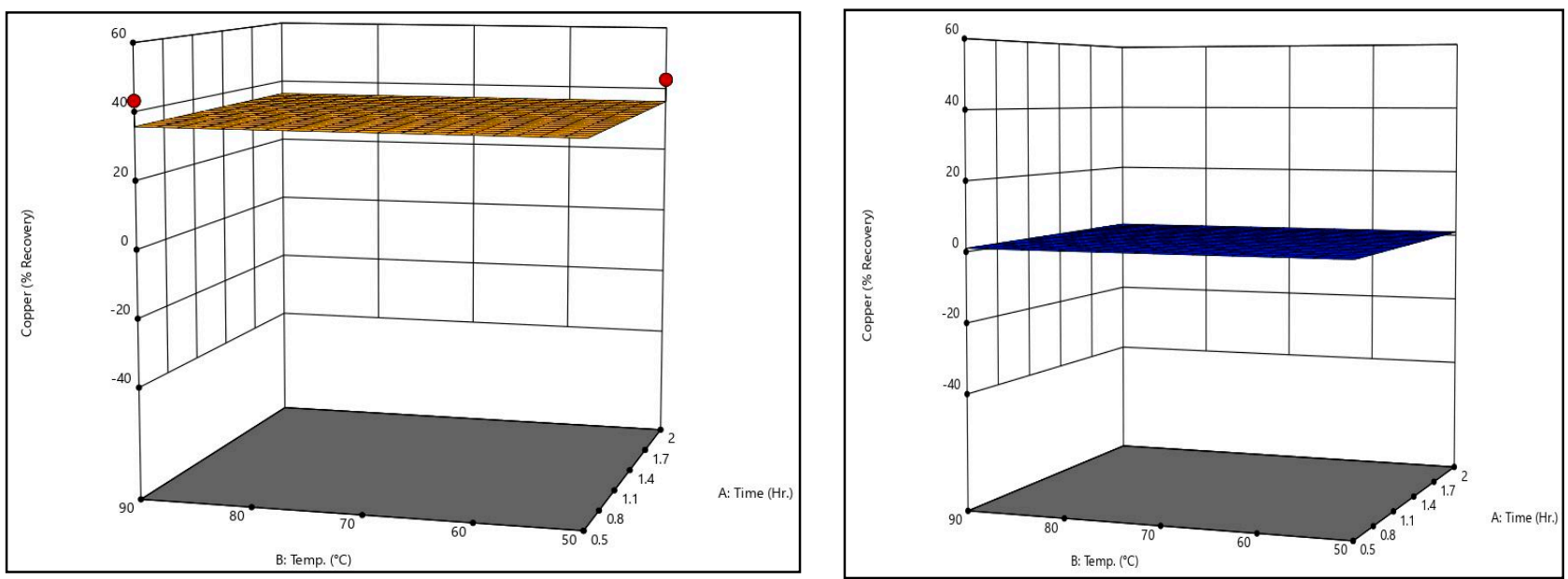

Figure 7. Caustic leaching copper recovery response surfaces: low alkalinity (left) and high alkalinity (right).

Figure 8 shows bismuth recovery response surfaces from the caustic leaching design matrix at the minimum and maximum temperatures tested. It can be seen that the surfaces are identical, meaning temperature has little to no effect on bismuth recovery. Additionally, it is evident that time has no meaningful effect on bismuth recovery. Only sodium hydroxide concentration has a measurable effect on bismuth recovery; higher sodium hydroxide concentrations are associated with higher bismuth recoveries. That said, it should be noted that increasing sodium hydroxide did not increase bismuth recovery by a meaningful degree within the ranges tested.
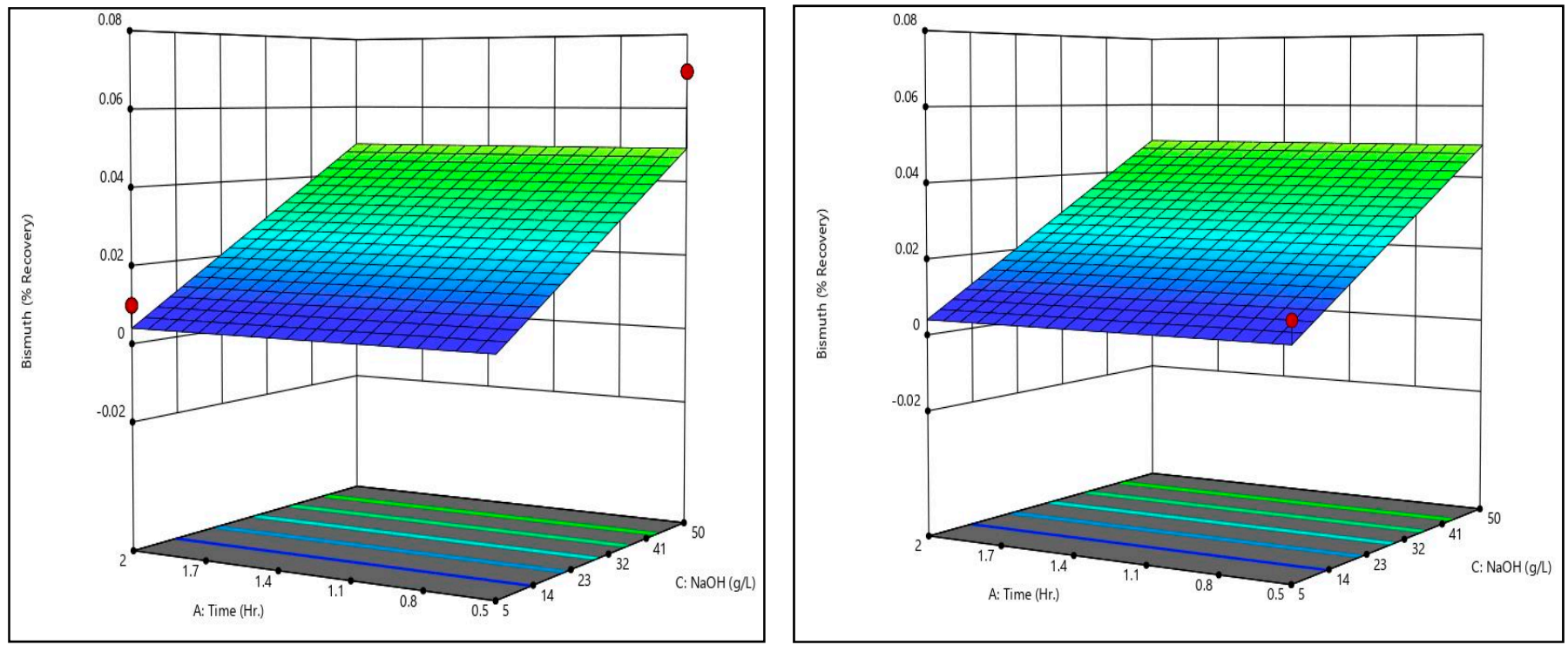

Figure 8. Caustic leaching bismuth recovery response surfaces: low temperature (left) and high temperature (right).

Figure 9 shows the arsenic recovery response surfaces from the caustic leaching design matrix at the minimum and maximum temperatures tested. Like bismuth recovery, temperature and time had no meaningful effect on arsenic recovery. Only sodium hydroxide concentration had an effect on recovery. Unlike bismuth, however, the effect of sodium hydroxide concentration was substantial; increasing sodium hydroxide concentration from $5 \mathrm{~g} / \mathrm{L}$ to $50 \mathrm{~g} / \mathrm{L}$ resulted in an increase of over $40 \%$ recovery. 

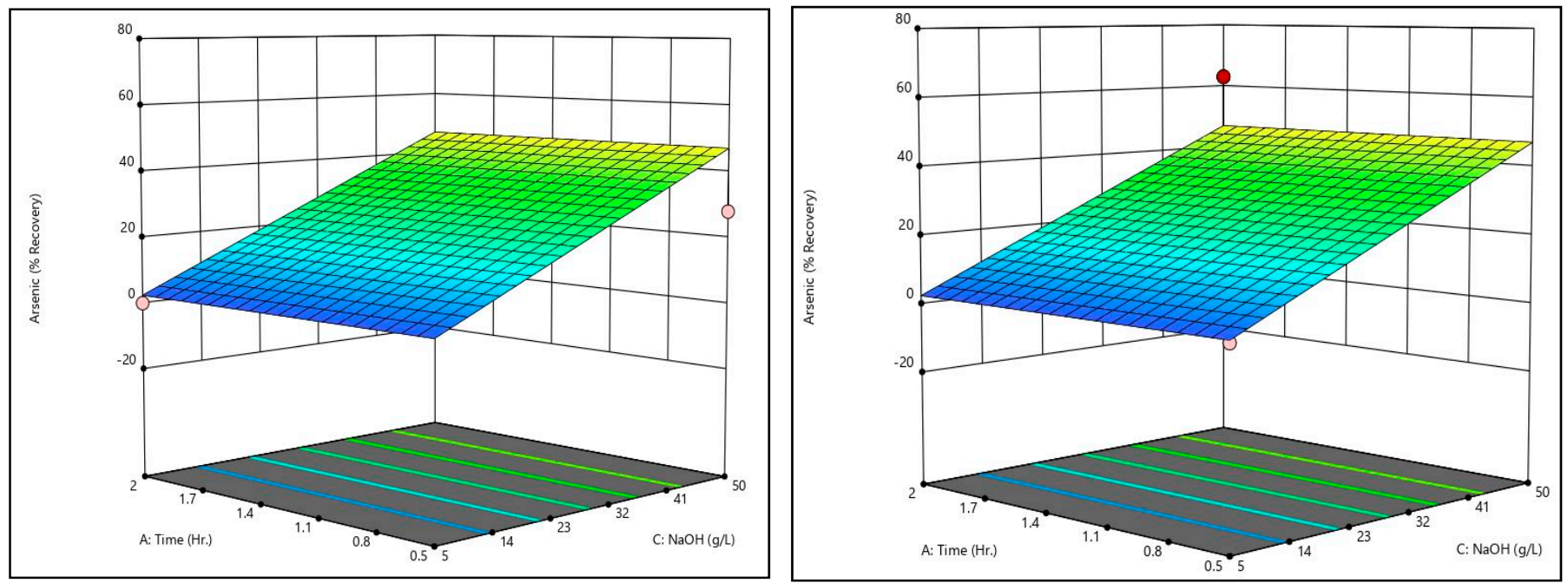

Figure 9. Caustic leaching arsenic recovery response surfaces: low temperature (left) and high temperature (right).

By comparing the caustic leaching response surfaces to the recovery data shown in Table 11, there is some discrepancy. Some trials exhibited recoveries substantially above or below the generated surfaces (see trial 4's arsenic recovery value, for example). On the surfaces themselves, this can be seen by the dots, which represent actual recovery values at the conditions shown. These discrepancies indicate that there may be some effect of time and temperature on arsenic recovery that is not statistically significant given the dataset. Additional data are necessary to confirm or refute this, however. It should be noted that other studies which have examined alkaline leaching of arsenic in metallurgical dusts have shown that increases in time and/or temperature improve arsenic recovery [22,23].

Both the surfaces and actual recovery values show that increasing sodium hydroxide concentration results in meaningful increases to arsenic recovery without meaningful increases to copper and bismuth recoveries, which remain near zero. Because of this, caustic leaching is a good candidate for separation of arsenic.

As shown in Table 10, sulfurous acid provided the second-highest copper recoveries to the leachate. Additionally, sulfurous acid provided a good separation between copper and bismuth. Sulfurous acid recovered approximately $70-80 \%$ of the copper to the leachate while only recovering, at most, $4.65 \%$ of the bismuth. A separation between copper and arsenic did occur, but only somewhat, given that between $25 \%$ and $30 \%$ of the arsenic was recovered for most trials. Lower arsenic recovery is necessary for a satisfactory copperarsenic separation.

The differences in recovery in bismuth and arsenic between the sulfurous trials and the sulfuric trials may be partially explained by the differences in the ending $\mathrm{pH}$ and Eh values for the two lixiviants. The sulfuric trials were more acidic and more oxidizing. In the case of bismuth, the data indicates that the sulfuric trials may have resulted in $\mathrm{Bi}^{3+}$ being the dominant phase rather than $\mathrm{Bi}(\mathrm{OH})_{2}^{+}$, which was the dominant phase in the sulfurous trials based on Figure 1. With arsenic, Figure 2 indicates that $\mathrm{H}_{3} \mathrm{AsO}_{4}$ or $\mathrm{H}_{3} \mathrm{AsO}_{3}$ may be the dominant phase for the sulfuric trials, while only $\mathrm{H}_{3} \mathrm{AsO}_{3}$ may be the dominant phase for the sulfurous trials. That said, neither difference in dominant phase would necessitate a strong separation beyond solubility differences; also, as stated, the Pourbaix diagrams do not utilize the phases present in the RTKC dust.

Figure 10 shows copper recovery response surfaces for the sulfurous acid trials at the maximum and minimum sulfurous acid concentrations tested. The low-acid condition indicates that at low temperatures, time has a negligible effect on copper recovery. The same can be said of temperature for short leaching times. That said, at higher values for either variable, the effect of increasing one of them becomes much more pronounced; increasing either results in increased copper recovery. By comparing the two surfaces, it 
can be seen that increasing the concentration of sulfurous acid serves to exaggerate this effect.
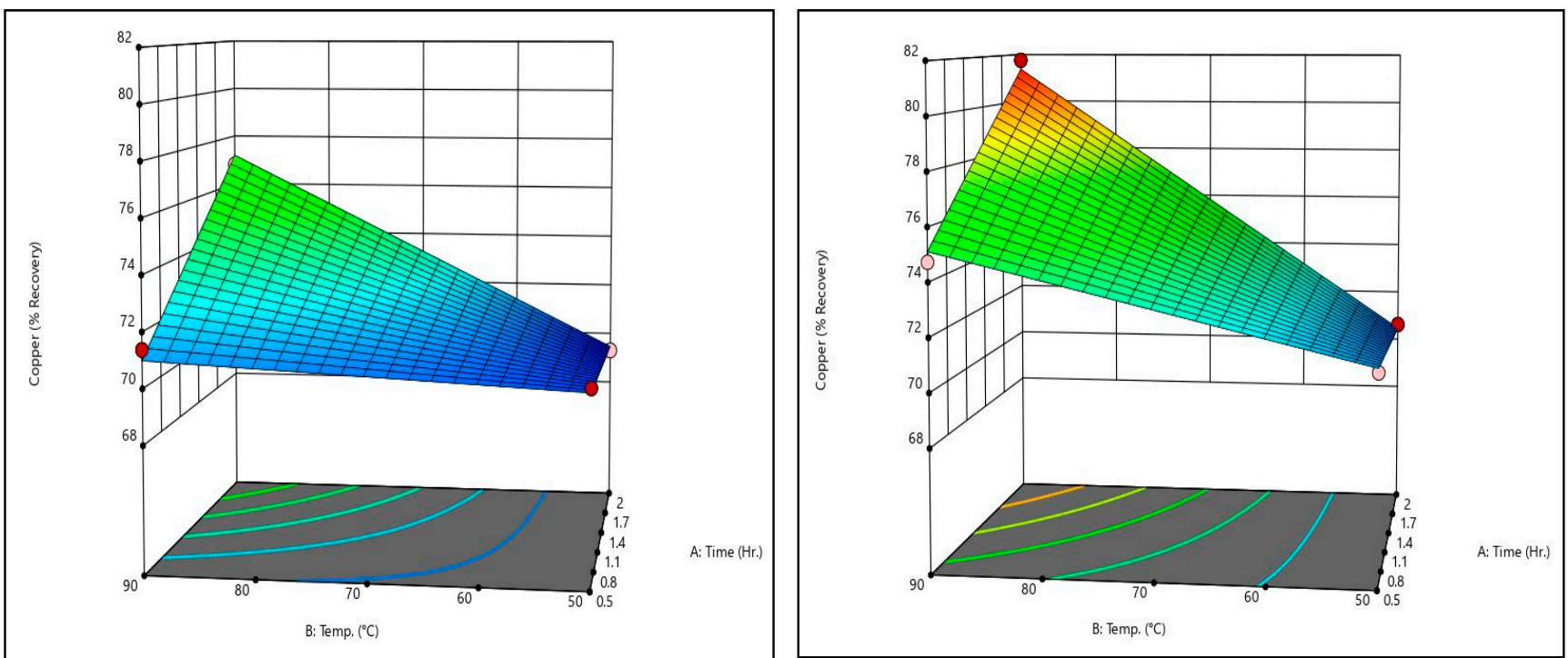

Figure 10. Sulfurous acid copper recovery response surfaces: low acid (left) and high acid (right).

Figure 11 shows bismuth recovery response surfaces for the sulfurous acid matrix at the minimum and maximum sulfurous acid concentrations tested. The low-acid surface shows that time does not have a substantial impact on recovery, and that higher temperatures are associated with higher bismuth recoveries. When compared with the low-acid surface, the high-acid surface indicates that increased sulfurous acid concentrations serve to reduce the effect of temperature, resulting in a "flatter" surface.
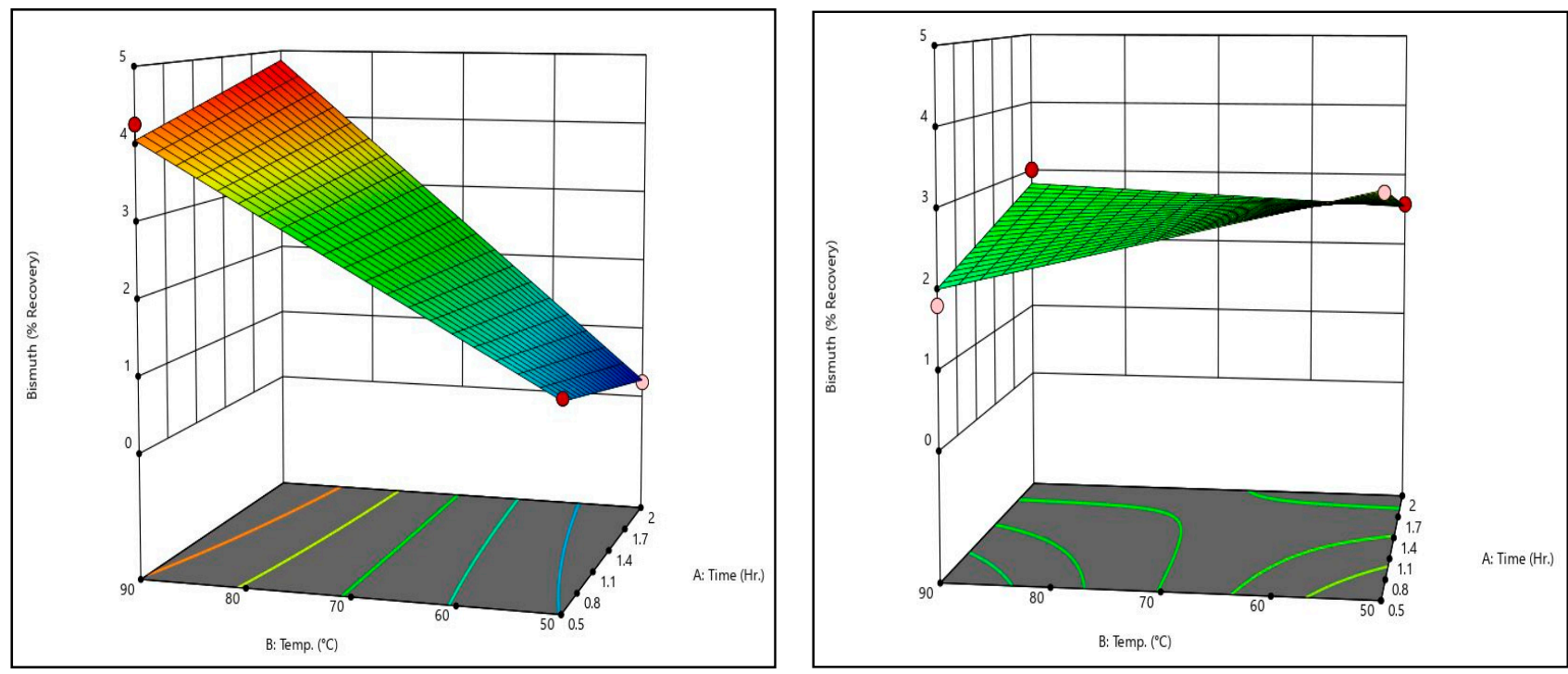

Figure 11. Sulfurous acid bismuth recovery response surfaces: low acid (left) and high acid (right).

Figure 12 shows arsenic recovery response surfaces for the sulfurous acid matrix at the minimum and maximum sulfurous acid concentrations tested. The low-acid surface shows that time and temperature, individually, have little effect on recovery. That said, increasing both results in increased arsenic recovery. By comparing the two surfaces, it can be seen that increased acid concentration serves to increase this effect so that it is more substantial. 

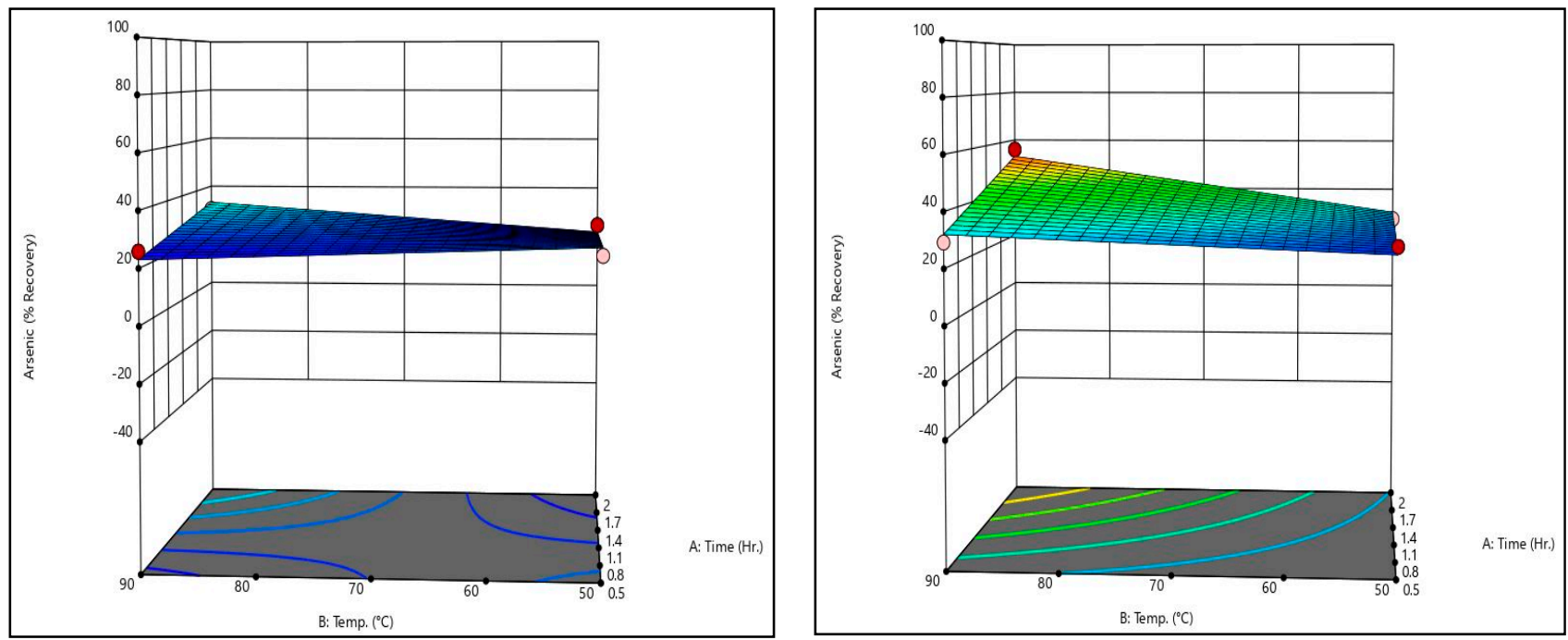

Figure 12. Sulfurous acid arsenic recovery response surfaces: low acid (left) and high acid (right).

By comparing the sulfurous acid response surfaces and the recovery data in Table 10, it can be said that an improved copper-bismuth separation is possible by increasing the sulfurous acid concentration. Bismuth sees reduced recoveries from increased acid, while copper sees increased recovery. Unfortunately, arsenic also sees improved recoveries from increased sulfuric acid, so sulfurous acid is only a good candidate for separation of bismuth.

In Table 11, it can be seen that water only recovered between $64 \%$ and $69 \%$ of the copper to the leachate. That said, water did provide an excellent separation between copper and bismuth, recovering essentially none of the bismuth. Additionally, water provided a good separation between copper and arsenic, recovering $7.86 \%$ arsenic on the high end. Given that bismuth is known to be more problematic than arsenic, the recovery values for bismuth and arsenic are very promising. Additionally, the recovery data indicate that neither time nor temperature had a substantial impact on the recoveries of copper, bismuth, or arsenic. This is confirmed by the water leach response surfaces below, and (in regard to copper and arsenic) agrees with Morales et al [12].

Figure 13 shows the copper recovery response surface for the water leach matrix. The surface indicates that at high conditions of either time or temperature, increasing the other has little effect on copper recovery. That said, when both are low, copper recovery is reduced, but by less than $5 \%$ recovery.

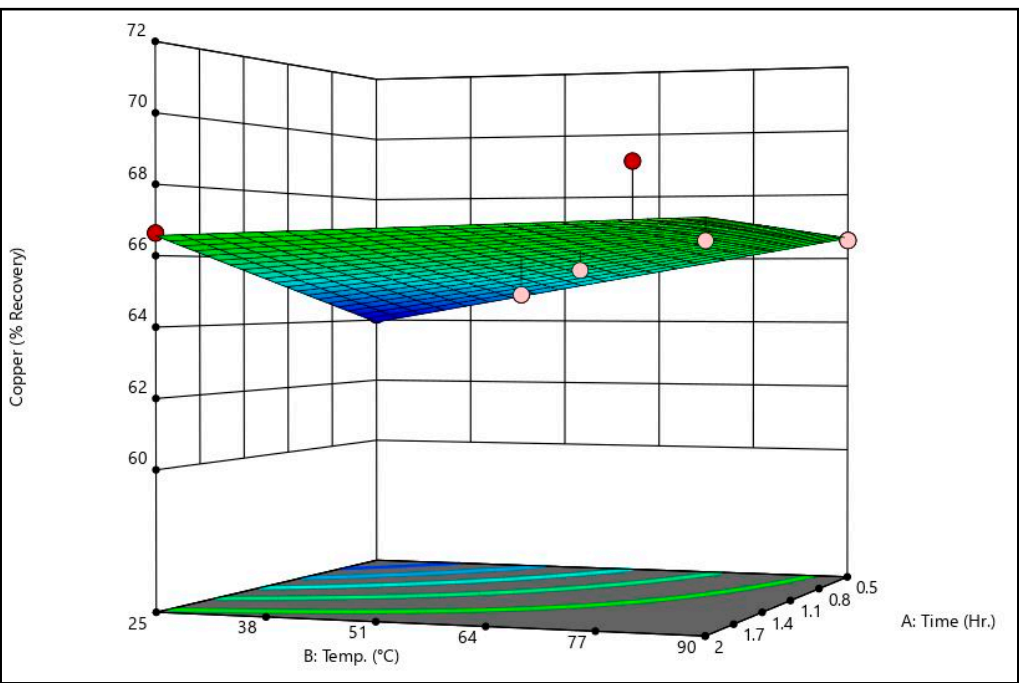

Figure 13. Water leach copper recovery response surface. 
Figure 14 shows the bismuth recovery response surface for the water leach matrix. The surface indicates that time has no measurable effect on bismuth recovery and that temperature does. Increases in temperature are associated with reduced bismuth recoveries. It should be noted that the overall range of bismuth recovery is less than $0.2 \%$ recovery. Therefore, temperature cannot be said to have a meaningful impact.

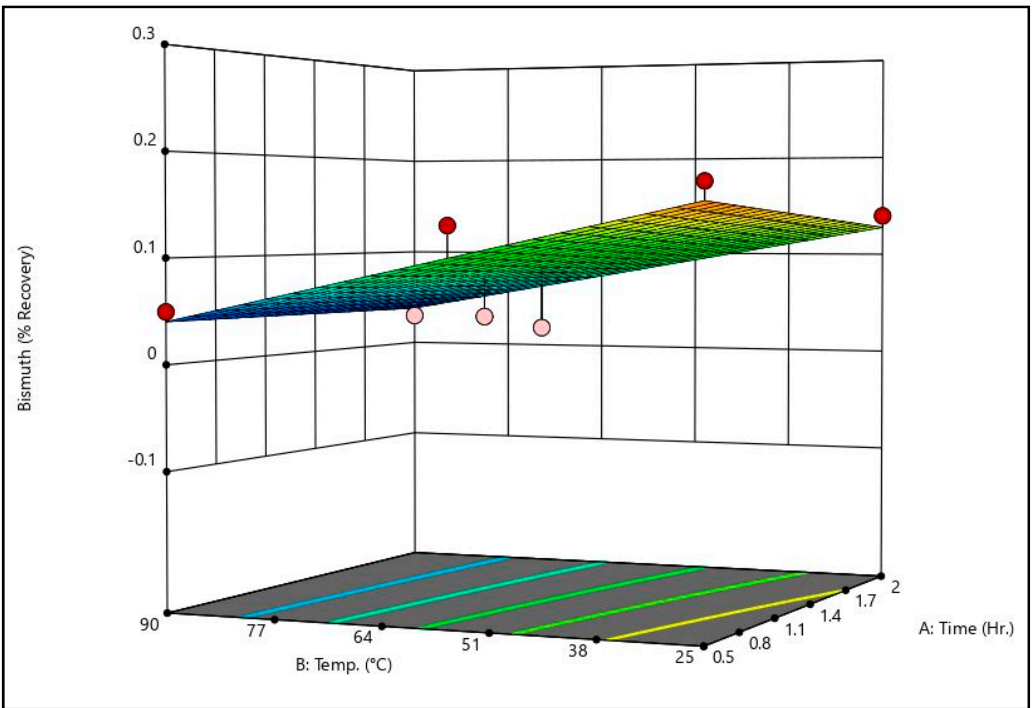

Figure 14. Water leach bismuth recovery response surface.

Figure 15 shows the arsenic recovery response surface for the water leach matrix. Like the bismuth surface, the arsenic surface indicates that time has no measurable effect and that higher temperatures are associated with reduced recoveries. Unlike bismuth, the range of arsenic recoveries is meaningful but still low, at approximately $3 \%$.

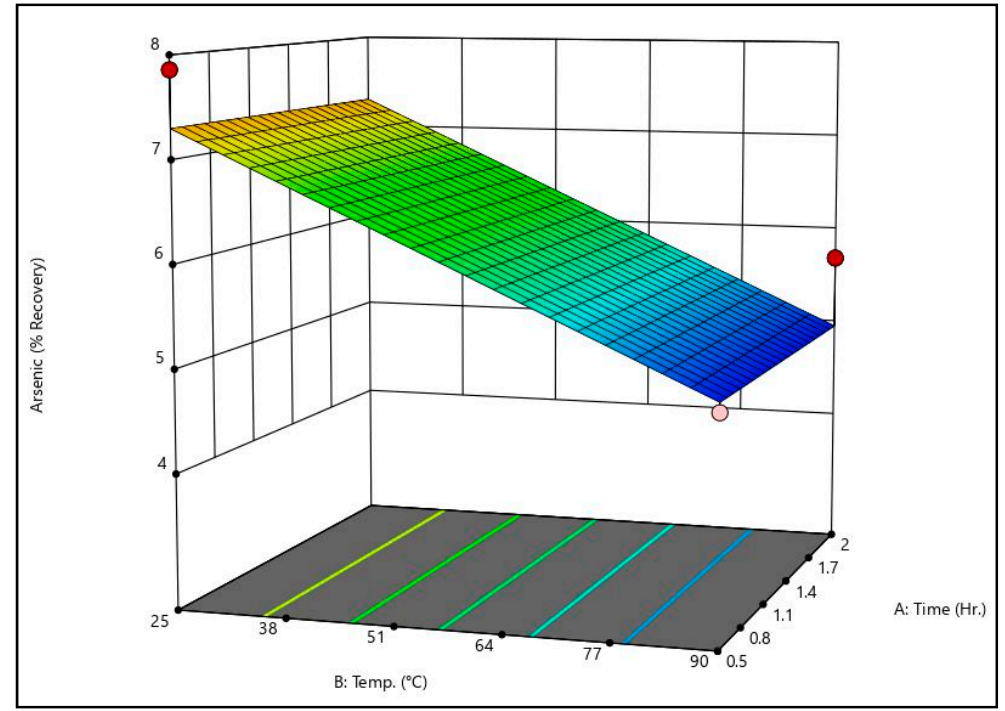

Figure 15. Water leach arsenic recovery response surface.

Generally, the recovery data for the leaching matrices agree with what should occur thermodynamically based on the Pourbaix diagrams. The sulfuric acid tests recovered all three elements, providing no separations between them. This makes sense when the $\mathrm{pH}$ and Eh data for sulfuric acid in Table 9 are considered, as the conditions provided by sulfuric acid cause soluble phases of all three elements to form based on the Pourbaix diagrams. 
Of the various lixiviants, only water provided a separation between copper and both bismuth and arsenic. When the data in Table 12 and the Pourbaix diagrams are considered, this makes sense, as water provided the thermodynamically correct (that is, fairly neutral and oxidative) conditions to separate copper from both bismuth and arsenic.

As shown in Table 11, the more alkaline trials of the caustic leach matrix were in the region of separation between copper and arsenic based on Figure 2, but not for copper and bismuth based on Figure 1; this agrees with the recovery data for the caustic trials, as only a copper-arsenic separation was achieved.

Interestingly, the conditions shown in Table 10 do not indicate that sulfurous acid should be able to generate a copper-bismuth separation. Based on Figure 1, the stable bismuth phase in the conditions generated by sulfurous acid is $\mathrm{Bi}(\mathrm{OH})_{2}^{+}$, which is a soluble phase. However, based on the recovery data, little bismuth was actually dissolved by the sulfurous acid. This may be due to the leach time being too short to allow for equilibrium.

Based on the data shown, there are two potential leaching methods for separation of bismuth and arsenic from copper in RTKC FF-ESP dust. One method is to use water, which transfers the majority of the copper to the aqueous phase and leaves behind the vast majority of the bismuth and arsenic in the residue.

Another method is to, first, leach with approximately $50 \mathrm{~g} / \mathrm{L}$ sodium hydroxide solution. This will leave the almost all of the copper and bismuth in the residue, while transferring potentially over $60 \%$ of the arsenic to the leachate. Given that arsenic is not nearly as problematic in electrorefining as bismuth, removing this amount may be satisfactory. Second, the caustic leach residue is leached with sulfurous acid. This should transfer the majority of the copper to the leachate while leaving the vast majority of the bismuth in the residue. A similar two-stage methodology has been proposed by Zhang et al. and shown to be effective [21]. A flowsheet for this process is shown in Figure 16. It should be noted that this was not tested, and therefore does not account for the necessary acid to react with any remaining sodium hydroxide or the possibility of unanticipated insoluble metastable phases during caustic leaching.

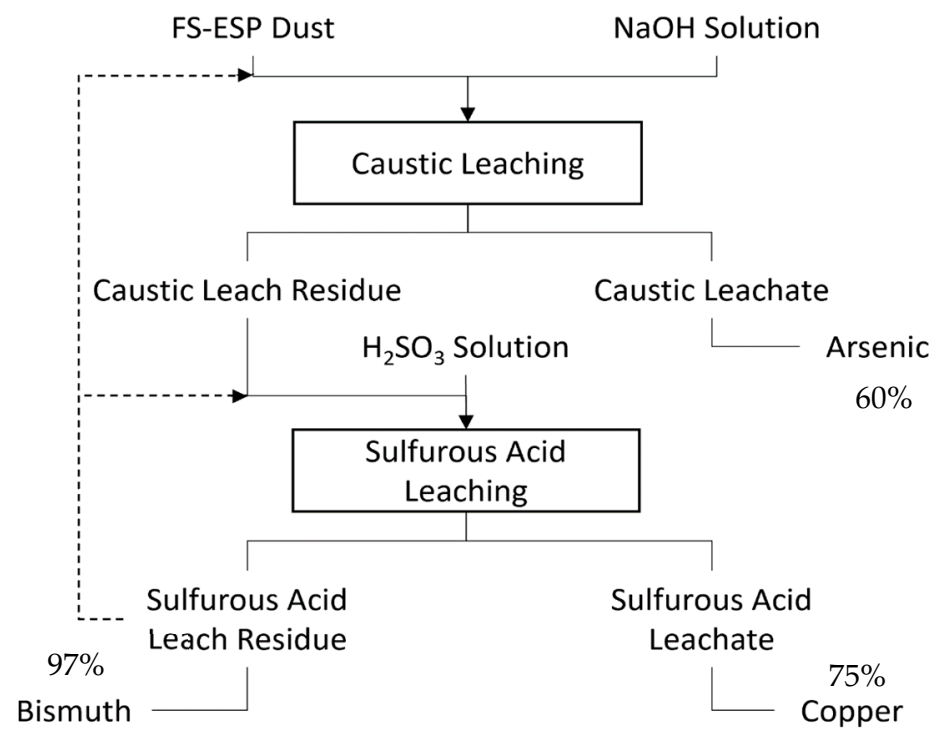

Figure 16. Proposed flowsheet for separation of copper from bismuth and arsenic. Approximate expected recoveries are shown in \%.

The benefits of the first method are lower arsenic and bismuth values and a lower operating cost, as virtually no expensive reagents are used. The benefit of the second method is higher copper recovery. Given that copper is the primary product of RTKC, this is an important consideration. It should be noted that whatever copper is not recovered may be leached again some number of times by the same or similar means. 


\section{Conclusions}

Characterization of FF-ESP dust, coupled with thermodynamic analysis and design of experiments for several leaching methods, resulted in the successful separation of copper from bismuth and arsenic in RTKC FF-ESP dust. Water leaching successfully separates both bismuth and arsenic. Caustic leaching successfully separates arsenic via leaching only arsenic under highly alkaline conditions. Sulfurous acid leaching successfully separates bismuth to a higher level than water leaching. It may be possible to get higher separations that what is possible with water leaching by combining caustic leaching and sulfurous acid leaching.

Differences in the expected separations based on the Pourbaix diagrams and the actual separations shown can be likely be attributed to deviations from ideality and interactions between the substances present in the diagrams and the actual materials. Ideally, thermodynamic data for the actual substances present would be generated, as this should allow for a better agreement between the implied separations based on Pourbaix diagrams and experimentation; such thermodynamic data would require either extensive modeling or determination via experimentation.

Continuation of this line of research should include testing of the process shown in Figure 16. Additionally, optimization studies using water and sulfurous acid as lixiviants with wider ranges among the tested variables, and testing for the effect of solid/liquid ratio during leaching, should be conducted with some focus on kinetic modeling. Other methods of alkaline leaching, such as pressurized alkaline leaching, should be pursued to determine if higher arsenic recoveries can be achieved. Moreover, further work regarding the upgrading of copper once in solution should be pursued. Such work should include the separation of copper and iron. This may be done via iron cementation with copper powder, but must be tested.

From an industrial standpoint, once in solution, the copper may be upgraded using a variety of ion-exchange or solvent-extraction methods, and then fed into an electrorefining circuit for production of metallic copper. Bismuth remaining in the leach residue is generally not considered hazardous and should not pose problems regarding disposal, though other elements in the residue, such as arsenic, may. Remaining arsenic could be dealt with via fixation with iron, which is fairly well established in the industry.

Author Contributions: Conceptualization, M.C., J.T., C.A. and S.W.; methodology, M.C and J.T.; investigation, M.C. and J.T.; resources, C.A. and S.W.; writing-original draft preparation, M.C. and J.T.; writing-review and editing, M.C. and C.A.; visualization, M.C.; supervision, C.A. and S.W.; project administration, C.A. and S.W.; funding acquisition, C.A. and S.W. All authors have read and agreed to the published version of the manuscript.

Funding: This research was funded by DOE CMI and Rio Tinto Kennecott.

Acknowledgments: The authors acknowledge Rio Tinto Kennecott Copper, the Colorado School of Mines Kroll Institute for Extractive Metallurgy, and Eagle Engineering. This research was supported by the Critical Materials Institute, an Energy Innovation Hub funded by the U.S. Department of Energy, Office of Energy Efficiency and Renewable Energy, and the Advanced Manufacturing Office.

Conflicts of Interest: The authors declare no conflict of interest.

\section{References}

1. Rio Tinto Kennecott. Available online: Riotintokennecott.com (accessed on 16 December 2020).

2. Total Materia. The Copper Flash CC Smelting Process. 2016. Available online: https://www.totalmateria.com/page.aspx?ID= CheckArticle\&site $=\mathrm{ktn} \& N M=394$ (accessed on 18 November 2020).

3. Yli-Penttila, J.T.; Peuraniemi, E.J.; Jokilaakso, A.; Riihilahti, K.M. Dust formation in flash oxidation of copper matte particles. Min. Met. Explor. 1998, 15, 41-47.

4. Okanigbe, D.O.; Popoola, A.; Adeleke, A.A. Characterization of copper smelter dust for copper recovery. Procedia Manuf. 2017, 7, 121-126.

5. Hiskey, J.B.; Chen, T.T. Mechanisms and Thermodynamics of Floating Slimes Formation. In Proceedings of the Honorary Symposium on Hydrometallurgy, Orlando, FL, USA, 11-15 March 2012; Elsevier B.V.: Amsterdam, The Netherlands, 2012. 
6. Fountain, C. The Whys and Wherefores of Penalty Elements in Copper Concentrates. In Proceedings of the MetPlant 2013: Metallurgical Plant Design and Operating Strategies, Perth, Australia15-17 July 2013; Australasian Institute of Mining and Metallurgy: Carlton, Australia, 2012

7. ASTM International. B115-10 Standard Specification for Electrolytic Copper Cathode; ASTM International: West Conshohocken, PA USA, 2016

8. Piret, N.L. Optimizing bismuth control during copper production. JoM 1994, 46, 15-18.

9. Mehta, A.K. Investigation of New Techniques for Control of Smelter Arsenic Bearing Wastes; U.S. EPA: Cincinnati, OH, USA, 1981.

10. Twidwell, L.G.; Mehta, A.K. Disposal of Arsenic Bearing Copper Smelter Flue dust. Nucl. Chem. Waste Manag. 1985, 5, $297-303$.

11. Ke, J.-J.; Qiu, R.-Y.; Chen, C.-Y. Recovery of metal values from copper smelter flue dust. Hydrometallurgy 1984, 12, $217-224$.

12. Morales, A.; Cruells, M.; Roca, A.; Bergo, R. Treatment of copper flash smelter flue dusts for copper and zinc extraction and arsenic stabilization. Hydrometallurgy 2010, 105, 148-154.

13. Ha, T.K.; Kwon, B.H.; Park, K.S.; Mohapatra, D. Selective leaching and recovery of bismuth as Bi2O3 from copper smelter converter dust. Sep. Purify. Technol. 2015, 142, 116-122.

14. Gupta, C.K. Chemical Metallurgy Principles and Practice; Wiley: Hoboken, NJ, USA, 2003.

15. Rosenqvist, T. Principles of Extractive Metallurgy; Tapir Academic Press: Trondheim, Norway, 2004.

16. Ichimura, R.; Tateiwa, H.; Almendares, C.; Sanchez, G. Arsenic Immobilization and Metal Recovery from El Teniente Smelter Dust. In Proceedings of the John E. Dutrizac International Symposium on Copper Hydrometallurgy, Toronto, ON, Canada, 25-30 August 2007.

17. Kovyazin, A.A.; Kochin, V.A.; Timofeev, K.L.; Krayuhin, S.A. Comprehensive Processing of Fine Metallurgical Dust. KnE Mater. Sci. 2020, 249-252. [CrossRef]

18. Yang, T.; Fu, X.; Liu, W.; Chen, L. Hydrometallurgical Treatment of Copper Smelting Dust by Oxidation Leaching and Fractional Precipitation Technology. JoM 2017, 69, 1982-1986.

19. Chen, Y.; Liao, T.; Li, G.; Chen, B.; Shi, X. Recovery of bismuth and arsenic from copper smelter flue dusts after copper and zinc extraction. Miner. Eng. 2012, 39, 23-28.

20. Liu, W.-F.; Fu, X.-X.; Yang, T.-Z.; Zhang, D.-C.; Chen, L. Oxidation leaching of copper smelting dust by controlling potenital. Trans. Nonferrous Met. Soc. China 2018, 28, 1584-1861.

21. Zhang, Y.; Jin, B.; Huang, Y.; Song, Q.; Wang, C. Two-stage leaching of zinc and copper from arsenic-rich copper smelting hazardous dusts after alkali leaching of arsenic. Sep. Purify. Technol. 2019, 220, 250-258.

22. Li, Y.; Liu, Z.; Li, Q.; Liu, F.; Liu, Z. "Alkaline oxidative pressure leaching of arsenic and antimony bearing dusts. Hydrometallurgy 2016, 166, 41-47.

23. Guo, X.-Y.; Yi, Y.; Shi, J.; Tian, Q.-H. Leaching behavior of metals from high-arsenic dust by $\mathrm{NaOH}^{-\mathrm{Na}} \mathrm{S}_{2} \mathrm{~S}$ alkaline leaching. Trans. Nonferrous Met. Soc. China 2016, 26, 575-580. 